\title{
Preface
}

\section{We're All in This Together}

T

his book is for landscape architects and contractors, commercial growers, golf course managers, park administrators, turf managers, and other stewards of the land. It is also for those in the position of hiring these people.

The organic approach is about a different way of thinking about landscaping, farming, gardening, pest control, and living in general. It's not just about switching products. It's about reading and studying and listening to get a better understanding of nature so you can make better decisions, grow better plants, improve our health, reduce costs, and be profitable, or at least stay within the budget if you are a nonprofit entity. Organic programs on a large scale can make a difference in the quality of our environment, our use of fossil fuels, and our climate. Let's face it: We are in an era of declining, more expensive resources. Whether it is water, fertilizer, or fossil fuels, the organic approach taken to the large scale has enormous potential to conserve resources and create a more sustainable future for everyone. After all, we are all in this together.

Critics say, "Organic programs might work in residential gardens, but they won't work on a large scale. They cost too much, don't control the pests, and are too much work." Food producers and many academics say, "We have to feed the world." Landscape managers say, "It's impractical." The truth is that natural organic programs work better in every way. They are easier to do on a large or commercial scale than on a small scale. Successful organic programs exist on all scales today, all over the world, although they aren't the mainstream yet. The United States has certified organic farms encompassing over one million acres and organic food sales totaling more than $\$ 7$ billion per year. Despite this, universities and agricultural extension agencies keep preaching that organics won't work and that the synthetic chemical approach is the only answer. People can't be kept in the dark much longer. 
Being organic on a commercial scale is no different from being organic in the backyard garden-just bigger. Yes, economics is a major factor. You'll learn that the front end of a project, during the soil-building stage, is the only possible time an organic program is more expensive. Those costs are not wasted, however, as they are with the synthetic approach. Expenses for materials and actions that build and improve the health of the soil are investments that pay off in the long term. These expenses also have immediate benefits for our environment by reducing erosion, conserving water, and sequestering carbon. In contrast, synthetic fertilizers and pesticides hurt the natural systems, and the damage accumulates with every application of toxic materials. The natural organic method is without doubt the more cost-efficient way to go. Properly designed organic programs can be switched to cold turkey at no more cost than the toxic chemical approach.

Natural organic products build the soil organic matter, stimulate life in the soil, and cause the soil to get better every year-forever. Toxic pesticides and high-nitrogen synthetic fertilizers, on the other hand, hurt the soil and pollute the environment. Every application reduces soil health until, one day, total failure occurs and replanting is needed. The end result is the destruction of the soil. The common explanation is "worn-out soil," which means a "dead soil" condition that is a self-inflicted casualty brought on by improper management. Conventional synthetic chemical farming and other growing operations are not sustainable. They waste money and continually deplete the soil of humus, water-holding capacity, mineral nutrients, beneficial life, and production capacity.

The natural organic method on a large scale is the only answer. Nature's method was in place and functioning perfectly on a global scale long before humans appeared on Earth. We can continue to make better and better decisions to improve the health of the soil, plants, pets, livestock, and people, but the basic program is just common sense. Natural organic horticulture and agriculture programs are productive and sustainable and need to be a big part of our future.

From the food we eat, to the air we breath, to the clothes we wear, humans depend on the thin covering of the earth's surface we call soil. Arguably, this thin and fragile layer of living topsoil is the earth's most critical natural resource. The quality of the soil determines, to a great degree, the condition of our air, water, and food, as well as the overall quality of all life on Earth. As you see later in this book, it is also a critical factor in the fight against global warming. Yet to most, soil is just plain dirt, understood by few and taken for granted by most. This book, however, is a celebration of soil and is focused on reversing soil destruction and building healthy soil. 
After only a half century of conventional agriculture using high-analysis synthetic fertilizers, the organic content of most farmlands has fallen way below a sustainable level, in some cases as low as one-tenth its original content. With the loss of the organic matter, rainwater or irrigation can no longer penetrate the soil fast enough to prevent it from running off, causing floods carrying topsoil and nutrients to the ocean. Loss of productive soil has created the so-called need for pesticides. Each year, more and more of these poisons are used. We are now using over 2 billion pounds per year in the United States. Pests are damaging more of our plants now than before modern artificial pesticides were invented. Toxic pesticides are good for one thing: keeping unhealthy plants alive. And it all keeps going downhill. Unhealthy plants affect the health of animals and people. Just as we have all participated in creating these problems, we all need to work together to find and implement solutions. The solution to many of the health issues in the world is organic management on a large scale. 
THIS PAGE INTENTIONALLY LEFT BLANK 
Organic Management for the Professional 
THIS PAGE INTENTIONALLY LEFT BLANK 